to 100 days; however, rereplacement of valves was considered in all and three died before the operation. Four patients underwent rereplacement of the prosthetic valve and only two survived the operation (Table II). No patient underwent simultaneous cholecystectomy. Our patient represents the eighth reported case of Salmonella prosthetic valve infection and only the third to have survived. Because of high mortality and recurrence rates of Salmonella PVE, early surgical intervention should be considered. For a diagnosis of PVE, transthoracic echocardiography did not disclose a vegetation before the operation in five of seven cases of Salmonella PVE, whereas TEE could detect a vegetation in both cases in which TEE was done. TEE should be done if PVE is suspected.

In Salmonella PVE with a possible infectious origin of the gallbladder, it is still controversial to perform simultaneous operations. The previous patients did not undergo simultaneous cholecystectomy. Salmonella species can persist in the gastrointestinal system, especially in the gallbladder, in carriers who are symptom-free. It is difficult to eradicate Salmonella in patients with gallstones or scarring of the biliary tree even after intravenous antibiotics. ${ }^{5}$ Some patients with Salmonella infection resistant to intravenous antibiotic therapy required cholecystectomy to eradicate the carrier state. ${ }^{5}$ One of two patients who survived after surgery for Salmonella PVE had recurrent fever after the operation, and Salmonella was isolated from his stool on the fifth postoperative day. In the Japanese literature, one patient with Salmonella PVE who survived after rereplacement of two prostheses had cholecystitis after the operation. Therefore simultaneous cholecystectomy should be considered in Salmonella PVE, especially in case of bile duct infection or gallstones, as in the present patient.

In summary, we described the eighth case of Salmonella PVE. Rereplacement of the aortic and mitral prosthetic valves and simultaneous cholecystectomy were done, without recurrence of the infection during 1 year of follow-up.

\section{REFERENCES}

1. Cohen PS, Maguire JH, Weinstein L. Infective endocarditis caused by Gram-negative bacteria: a review of the literature, 1945-1977. Prog Cardiovasc Dis 1980;22:205-42.

2. Yamamoto N, Magidson O, Posner C, Mendez MA, Zubiate P, Kay JH. Probable Salmonella endocarditis treated with prosthetic valve replacement: a case report. Surgery 1974;76: 678-81.

3. Choo PW, Gantz NM, Anderson C, Maguire H. Salmonella prosthetic valve endocarditis. Diagn Microbiol Infect Dis 1992; 15:273-6.

4. Lee Y, Lai L, Shyu K, Kuan P, Lien W. Salmonella prosthetic valve endocarditis: a case report. J Vase Dis 1994;45:245-7.

5. Neil MA, Opal SM, Heelan J, et al. Failure of ciplofloxacin to eradicate convalescent fecal excretion after acute salmonellosis: experience during an outbreak in health care workers. Ann Intern Med 1991;114:195-9.

\title{
UNUSUAL COMPLICATION SEVEN YEARS AFTER SUCCESSFUL AORTIC RECOARCTATION REPAIR WITH A DACRON GRAFT: ACUTE THROMBOEMBOLIC LEG ISCHEMIA CAUSED BY A MOBILE THROMBUS AT THE DISTAL SUTURE LINE
}

\author{
R. Berzins, MD, ${ }^{\text {a }}$ C. H. Attenhofer, MD, ${ }^{\mathrm{b}}$ L. K. von Segesser, MD, ${ }^{\mathrm{c}}$ M. Hauser, MD, ${ }^{\mathrm{d}}$ M. Turina, MD, ${ }^{\mathrm{c}}$ and

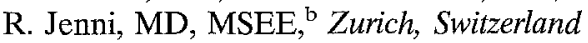

Uncorrected coarctation of the aorta is associated with a substantially shortened life expectancy. ${ }^{1}$ Corrective surgery for this condition was introduced in 1944. Resection

From the Department of Surgery, ${ }^{a}$ Division of Echocardiography, ${ }^{b}$ Clinic for Cardio-Vascular Surgery, ${ }^{c}$ and Department of Medical Radiology, ${ }^{d}$ University Hospital Zurich, Switzerland.

Received for publication August 1, 1995; accepted for publication Nov. 7, 1996.

Address for reprints: Rolf Jenni, MD, MSEE, Division of Echocardiography, University Hospital Zurich, Rämistr. 100, 8091 Zurich, Switzerland.

J Thorac Cardiovasc Surg 1996;112:842-4

Copyright (C) 1996 by Mosby-Year Book, Inc.

$0022-5223 / 96 \$ 5.00+0 \quad \mathbf{1 2 / 5 4 / 7 0 5 3 5}$ and end-to-end anastomosis, extended end-to-end repair, prosthetic patch aortoplasty, prosthetic interposition grafts, subclavian flap aortoplasty, ascending aorta-descending aorta bypass, and balloon angioplasty have all been used in coarctation repair and have improved survival. $^{2,3}$ The increases in late morbidity and mortality after coarctation repair are primarily related to anastomotic site complications such as recoarctation or pseudoaneurysms and associated cardiovascular disease such as bicuspid aortic valve, mitral valve lesions, ventricular septal defect, and persistent systemic hypertension and its sequelae. An unusual case of peripheral arterial embolism caused by an anastomotic site complication is presented.

Case report. A 22-year-old man was admitted to the emergency department because of acute left leg ischemia. 
At the age of 1 month, he had undergone classic coarctation repair with resection and end-to-end anastomosis for a postductal aortic coarctation with no associated cardiovascular anomalies but untreatable congestive heart failure. Sixteen years later, coarctation recurred with a maximal systolic pressure gradient of $65 \mathrm{~mm} \mathrm{Hg}$, resulting from luminal narrowing with a minimal diameter of $7 \mathrm{~mm}$. During the operation, diminished aortic wall quality was noted at the prior site of anastomosis and necessitated resection from the distal aortic arch to the intercostal arteries with interposition of a $20 \mathrm{~mm}$ USCI woven Dacron graft (Bard Inc., USCI Division, Billerica, Mass.). Continuous 3-0 and 4-0 Prolene sutures (Ethicon, Inc., Somerville, N.J.) were used. The postoperative recovery and follow-up were uneventful.

The patient was then free of symptoms for 6 years until 2 days before the current admission, when claudication of the left lower leg developed, followed by leg pain at rest. On admission, the left leg was cold, the left femoral pulse weak, and the left popliteal and peripheral pulses were absent. The right arm blood pressure was $135 \mathrm{~mm} \mathrm{Hg}$. The peripheral pressure was not measurable on the left side but was normal on the right side.

Findings on the electrocardiogram (sinus rhythm) and chest $\mathrm{x}$-ray film were within normal limits. Digital subtraction angiography of the left leg showed thrombotic occlusion of the left external iliac artery and the left common femoral artery. The abdominal aorta was normal. In the region of the Dacron graft, an irregular lining of the graft with mild dilatation of the native aorta distal to the graft was observed. Transesophageal echocardiography demonstrated thrombotic apposition at the site of the distal anastomosis with adherence of two mobile thrombi but no evidence of dissection, aneurysm, or pseudoaneurysm formation. The transition between the graft and the descending thoracic aorta was unremarkable. No significant gradient was measurable at the prior coarctation site. Coagulation studies (including functional antithrombin III, protein $\mathrm{C}$, and protein $\mathrm{S}$ levels) were within the normal range.

Emergency embolectomy was performed. During the operation, several dark red emboli were removed, the largest being 22 by $11 \mathrm{~mm}$. The histologic characteristics were consistent with some older thrombi, with predominantly fresh appositional thrombus material. The postoperative course was uneventful, and signs of claudication resolved completely. The peripheral pulses are now palpable. The patient was started on a regimen of oral anticoagulants and acetylsalicylic acid. At 3 months' follow-up the patient was free of symptoms, and in the transesophageal echocardiogram the extension of the thrombotic material attached to the aortic wall had regressed substantially. Careful long-term follow-up every 6 months with transesophageal echocardiography is planned.

Discussion. Surgical correction of aortic coarctation has been successfully performed for more than four decades with better long-term results than those achieved with medical management. ${ }^{1-3}$ However, survival is still shorter than expected. ${ }^{3}$ Causes of premature death are coronary artery disease $(37 \%)$, sudden death $(13 \%)$, heart failure (9\%), cerebrovascular accident $(7 \%)$, ruptured aortic aneurysms $(7 \%)$, perioperative death after a subsequent operation $(7 \%)$, or other reasons $(20 \%) .{ }^{3} \mathrm{Up}$ to $30 \%$ of patients have residual or recurrent coarctation after repair (necessitating reoperation in $3 \%$ to $5.4 \%$ ), systemic hypertension, aneurysms, pseudoaneurysms, and other cardiovascular complications. ${ }^{3}$ In our patient, restenosis was diagnosed 16 years after the initial classic end-to-end anastomosis. At the restenosis operation, an extended resection was necessary with the interposition of a Dacron graft because of the complex local site with extensive aortic wall changes. Six years after placement of this Dacron graft, the surprising embolic event occurred. Prosthetic interposition grafts have been used since 1960 in coarctation repair and are useful in selected cases, especially if the ends of the transected aorta cannot be approximated. Known long-term complications of Dacron aortic grafts include dilatation of the prosthetic grafts and false or, rarely, true aneurysms at the anastomotic site; such complications have also been described after coarctation repair. ${ }^{4}$ Other complications, such as dehiscence of the proximal suture line of a Dacron tube graft resulting in a flap-valve effect and acute functional occlusion of the aorta, are rare. ${ }^{5}$ A graft has a different compliance than the native aortic wall and thereby causes turbulence, which can induce aortic wall changes such as cystic medial necrosis and intimal damage. These changes may predispose to thrombus apposition. However, peripheral embolism after a Dacron aortic graft is rare and, if present, most commonly is the result of pseudoaneurysm formation.

Coagulation studies excluded an inherited disorder with disposition to arterial thrombosis. This case is therefore exceptional. The patient had no pseudoaneurysm formation and still had an embolic event as a result of local thrombus apposition. No similar case has ever been published. Careful life-long follow-up is necessary in patients after coarctation repair; follow-up examinations normally include assessment of hypertension at rest and during exercise and of possibly associated cardiovascular anomalies. The complication that occurred in this patient indicates that follow-up should also include assessment of the repair site excluding recoarctation, pseudoaneurysm or aneurysm formation, dilatation of an interposed graft, or local thrombus formation. The value of transesophageal echocardiography, computed tomography, and magnetic resonance imaging for the assessment of disease of the thoracic aorta have been widely demonstrated. However, they are also useful in the follow-up evaluation of coarctation repair for assessing pressure gradients, associated cardiac anomalies, and, as shown, the local repair site. Any embolic event in a patient after aortic repair makes careful assessment of the repair site compulsory.

\section{REFERENCES}

1. Presbitero P, Demarie D, Villani M, Perinetto EA, Riva G, Orzan F, et al. Long term results (15-30 years) of surgical repair of aortic coarctation. Br Heart J 1987;57:462-7. 
2. Bobby JJ, Emami JM, Farmer RDT, Newman CGH. Operative survival and 40 year follow up of surgical repair of aortic coarctation. Br Heart J 1991;65:271-6.

3. Cohen M, Fuster V, Steele PM, Driscoll D, McGoon DC. Coarctation of the aorta: long-term follow-up and prediction of outcome after surgical correction. Circulation 1989;80: 840-5.
4. Del Nido PJ, Williams WG, Wilson GJ, Coles JG, Moes CAF, Hosokawa Y, et al. Synthetic patch angioplasty repair of coarctation of the aorta: experience with aneurysm formation. Circulation 1986;74(Suppl):I32-6.

5. Williams CR, Nilakhe V, Clouse ME. Acute aortic occlusion as a late complication of coarctation repair. Cardiovasc Intervent Radiol 1989;12:286-9.

\title{
ENDOBRONCHIAL TUMOR EMBOLISM: A PREVENTABLE CAUSE OF DEATH
}

\author{
V. Pathi, FRCS, MRCP, P. Ramphal, MBBS, F. Sutherland, FRCS, and A. Kirk, MD, FRCS, Glasgow, Scotland
}

During the past decade, improvements in anesthesia and surgical techniques have made pulmonary resection amongst the safest of major operative procedures. The routine use of the double-lumen endotracheal tube has allowed the operation to be carried out in a more comfortable manner, maintaining oxygen saturation without

From the Department of Cardiothoracic Surgery, Western Infirmary, Dumbarton Rd., Glasgow, Scotland, United Kingdom.

Received for publication Jan. 24, 1996; accepted for publication Feb. 5, 1996.

J Thorac Cardiovasc Surg 1996;112:844-5

Copyright $(1096$ by Mosby-Year Book, Inc.

$0022-5223 / 96 \$ 5.00+0 \quad \mathbf{1 2 / 5 4 / 7 2 5 6 0}$ obscuring the operative field. We report a case in which the inability to pass such a tube led to disastrous consequences.

Case report. A 76-year-old woman had a history of breathlessness, cyanosis, and left-sided chest pain. Clinical examination and chest radiography confirmed complete collapse of the left lung (Fig. 1). Bronchoscopy was performed and revealed tumor originating from the left upper lobe and involving the left main bronchus. A carcinosarcoma was proved by histologic examination. Because mediastinoscopic results were negative for nodal involvement, the patient was prepared for operation.

In the anesthesia room, a long $8 \mathrm{~F}$ single-lumen endotracheal tube was inserted for ventilation because of the small size of the patient's trachea. A routine left thora-

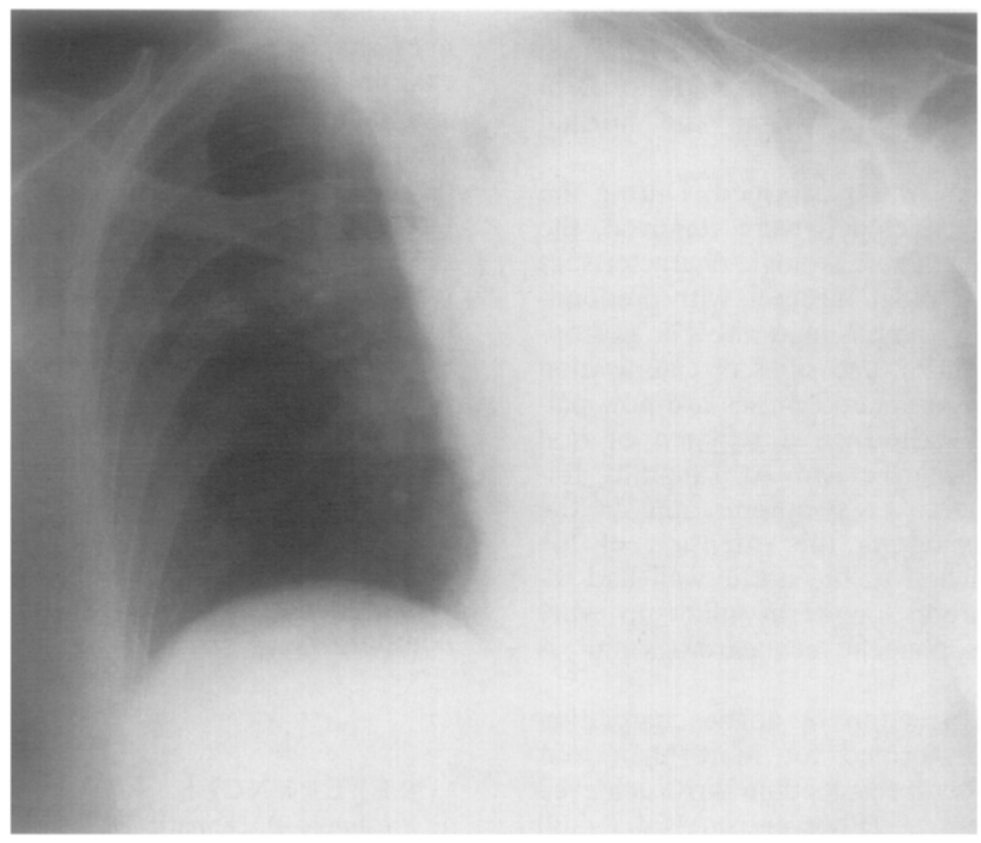

Fig. 1. Chest radiograph of patient displays complete collapse of left lung. 